\title{
Rapid improvement of reading performance in children with dyslexia by altering the reading strategy: A novel approach to diagnoses and therapy of reading deficiencies
}

\author{
Reinhard Werth* \\ Institute for Social Pediatrics and Adolescent Medicine, Ludwig-Maximilians-University of Munich, Munich, \\ Germany
}

\begin{abstract}
.
Background: Reading disability is termed "dyslexia" if it is much lower than other cognitive abilities according to the intelligence quotient (IQ). This means that dyslexia is caused by an impairment of abilities other than those which the IQ requires. Therefore, reading performance should improve immediately if these impairments are either eliminated or compensated.

Objectives: The experiments explore conditions under which these impairments are compensated and dyslexic children's poor reading ability immediately improve.

Methods: Experiment 1 examined if reducing the number of letters in pseudowords, prolonging the time interval during which the gaze is directed to pseudowords, reducing the amplitude of saccades and prolonging the time interval that elapsed between the beginning of the presentation of a pseudoword and the beginning of the pronunciation of that word influences childrens' reading performance. A group of 100 German children ( 71 boys and 29 girls) aged 8 to 13 years, who suffered from dyslexia according to the Zuerich Reading Test, were divided into a training group $(n=50)$ and an age-matched control group $(n=50)$ and tested. Both groups participated in experiment 1 . Only the children in the training group participated in experiment 2 , in which the children learned a compensatory reading strategy. The age - matched control group did not learn the compensatory reading strategy. In the training group, reading performance was tested before and after having learned the new reading strategy.

Results: Conditions were found under which all children were able to read $95 \%$ of the pseudowords correctly. After having learned a compensatory reading strategy, a mean $58.9 \%$ decrease in words read incorrectly was found after a single training session. The difference between the number of reading mistakes before and after the training session was highly significant (Wicoxon Test: $p<0.00001$ ). The effect size showed that the compensatory reading strategy was highly effective (Hedges $g=1.7)$. The reading ability of an age-matched dyslexic control group showed no improvement.
\end{abstract}

Conclusions: Dyslexic subjects' reading performance improves significantly when they learn a new reading strategy.

Keywords: Dyslexia, diagnosis, therapy, word recognition, segmentation, fixation time, eye movements, speech onset latency

\footnotetext{
${ }^{*}$ Corresponding author: Prof. Dr. Reinhard Werth, Institute for Social Pediatrics and Adolescent Medicine, LudwigMaximilians-University of Munich, Germany, Haydnstr. 5 D-80336 Munich, Germany. Tel.: +491733550232; E-mail: r.werth@1rz.uni-muenchen.de.
}

\section{Introduction}

Between 5 and $15 \%$ of school children in the USA (Shaywitz et al., 1990, Katusic et al., 2001, Rutter et al., 2004) and about $15 \%$ of 
German-speaking fourth graders (Bos et al., 2012) suffer from reading disturbances. An impaired reading ability is called "dyslexia" if it is much (about two standard-deviations) below other cognitive abilities according to the intelligence quotient (IQ) (Stein 2001; Lyon et al., 2003; Fletcher 2009). This means dyslexia is caused by an impairment of abilities other than those which the IQ requires. A diagnosis of dyslexia must exclude poor reading due to sensory impairments, such as reduced visual acuity, a visual-field defect, an elevated luminance-difference threshold, deafness, or impaired speech perception. Dyslexia may, however, be the result of other impairments that are indispensable prerequisites for fluent reading.

It has been shown that phonologic impairment (Farah et al., 1996), a spatial cuing deficit in visual attention (Roach \& Hogben 2004), an auditoryprocessing disorder (King et al., 2003), a reduced ability in the temporal processing of stimuli (Tallal et al., 1993; Nagarajan et al., 1999), visual crowding, unusual foveal and parafoveal information processing (Geiger \& Lettvin 1987, Atkinson 1997; Lorusso et al., 2004), a deficit in shifting covert visual attention (Buchholz, Davis 2005), and poorer saccadic control (Biscaldi et al., 2000; Fischer \& Hartnegg 2000) are more frequent in children with dyslexia than in normal readers.

Even if sensory, cognitive and/or motor impairments are present in a group of poor readers and absent in a group of normally reading children, this does not necessarily indicate a causal relationship between these impairments and poor reading abilities. Therefore, it is questionable if these disturbances have an impact on reading ability (Skoyles \& Skottun 2004; Tree \& Kay 2006). It has become increasingly clear that dyslexia is a disorder that is not always caused by one single disturbance, but may have many different causes (King et al., 2007; Tamboer et al., 2014; Moura et al., 2017). During the last decades, neurobiological research has confirmed that dyslexia is an impairment of different neuronal networks that are distributed over frontal, parietal, temporal, and occipital areas in the brain and of a disruption of their connections (Shaywitz \& Shaywitz 2005; Wandell et al., 2012; Ashkenazi et al., 2013; Costanzo et al., 2016; Black et al., 2017).

The fact that different brain regions are involved in the reading process becomes apparent when one considers the different abilities that are indispensable for fluent reading. One of the necessary presuppositions for correct and fluent reading is that the reader fixates the right location within a word, that s/he is able to visually process several letters simultaneously, and that s/he fixates a word or word segment for a given time interval. After the end of the fixation time that is needed to recognize the word or word segment, saccades of a given amplitude have to be programmed and executed, the correct phonemes have to be retrieved from memory, words or wordsegments have to be stored in memory and have to be composed into sentences, and a meaning has to be given to the words and sentences. An impairment of one or more of these abilities and a functional impairment of the cerebral areas that mediate these abilities may cause a reading disability.

Reading disorders can be treated either by improving or compensating the impaired ability that causes the reading deficiency. Improving impaired ability means restoring the underlying diminished neuronal function.

Functionally impaired neural networks can often only recover to a certain extent, and even partial recovery takes a long time. Therefore, reading therapies to improve impairments causing dyslexia are time consuming and only have limited effects. Galuschka et al. (2014) found an effect in their literature survey only after at least 20 weeks of therapy, but even then the effect size was limited. We developed a reading strategy to reduce the number of reading errors within a short period of time by compensating the existing neuronal deficits instead of seeking to improve impaired neural functioning. The effect of the reading therapy can be proven only if all variables relevant for improving reading performance can be controlled, and this is only possible if the improvement in reading performance takes place within one session. Therefore, it was examined if (1) the number of letters that make up a word, (2) the time interval during which the gaze was directed to a word, (3) the time interval that elapsed between the beginning of the fixation of a word and the beginning of the pronunciation of the word, and (4) the amplitude of saccades during reading could be altered to improve the reading performance of dyslexic readers within one session.

\section{Patients}

A group of 100 children ( 71 boys and 29 girls) aged 8 to 13 years who were diagnosed as dyslexic according to the Zuerich Reading Test (ZRT) participated in the experiments. All children were native German speakers and right-handed. They had no 
neurological, psychiatric, visual, or auditory deficits and no speech disorders. The children were diagnosed as dyslexic according to the ZRT. The childrens' IQs were within the normal range.

The children were second-to-sixth graders who knew all individual letters, had approximately the same lessons in reading, and were expected to read fluently, but were far behind the required reading ability. Before experiments 1 and 2, the children were requested to read one half of cards 3,4 , and 5 of the ZRT and to read the other half of this test after experiments 1 and 2 .

\section{Methods}

\subsection{Procedure}

The children were randomly assigned to a therapy group ( 36 boys and 14 girls, mean age 121.4 months, SD 13.7 months) and a control group ( 35 boys and 15 girls, mean age 116.5 months; SD 13.2 months). The children's ages in both groups did not significantly differ ( $t$-test: $p>0.07)$. Both groups participated in experiment 1 . Only the therapy group participated in experiment 2 , in which the children received compensatory reading training. Each group was again randomly divided into two age-matched groups, A and $\mathrm{B}$, each containing an equal number of children. Therapy group A of each experiment read the first part of the ZRT first and the second part after having learned the compensatory reading strategy. Control group A read the first part of the ZRT first and the second part after having read a text without learning the compensatory reading strategy. Therapy group B read the second part of the same reading test first and the first part after having learned the compensatory reading strategy. Control group B read the second part of the same reading test first and the first part after having read a text without having learned the compensatory reading strategy.

\subsubsection{Experiment 1: Tachystoscopic investigation of the improvement in word recognition in dyslexic children}

Pronounceable 2-, 3-, 4-, 5-, or 6-letter pseudowords were presented at eye level on a monitor to examine the role of the length of time that the gaze must be directed to a word or word - segment of a given length to recognize it. The distance between the eyes and the monitor was $40 \mathrm{~cm}$. The words were black (luminance of $4 \mathrm{~cd} / \mathrm{m}^{2}$; altitude $14 \mathrm{~mm}$; space between types: $4 \mathrm{~mm}$ ) on a background of $68 \mathrm{~cd} / \mathrm{m}^{2}$. The presentation times varied between 250 and 500 milliseconds. The sequences of the letters in the pseudowords also occurred in colloquial German words. A sequence of 20 pseudowords of the same length was shown for the same time interval in each experiment. Each trial began with the presentation of a fixation mark (luminance: $28 \mathrm{~cd} / \mathrm{m}^{2}$ ) in the center of the monitor. The child was asked to direct his/her gaze to the fixation mark. When the child maintained fixation, the fixation-mark disappeared and was replaced by a pseudoword. The middle of the pseudoword was at the same location as the fixation point had been before. The children were to read the pseudoword aloud. If the child did not pronounce the word correctly, s/he was asked to spell the word and write the word. After a time interval of between 5 and $10 \mathrm{sec}-$ onds, the green fixation mark was presented again. When the child fixated the fixation mark, a different pseudoword appeared for the same time interval as the previously shown pseudoword. A list of 20 pseudowords was similarly presented in succession. If more than one word out of 20 was not read correctly, it was investigated whether the mistakes were because the child had started to pronounce the word too early. This examined the role of a prolongation of the time interval between the beginning of the presentation of the word and the beginning of the pronunciation for correct reading. The experiment was repeated with a different list of 20 pseudowords, each containing the same number of consonants and vowels at the same location within the word. A tone was presented at a given time after the onset of the presentation of the pseudoword to prolong the time interval between the onset of the presentation of the pseudoword and the onset of its pronounciation. In the first trial, the time interval was prolonged for 1 second. If this time interval was not sufficient for correct word recognition, the time interval was prolonged in increments of 1 second until at least $95 \%$ of the pseudowords were read correctly. The children did not get any feedback about their performance.

The childrens' reading performance was registered by recording their voice with a microphone; the signal was amplified, filtered, and stored. Fixation was controlled using an infrared-light-reflecting, eye-tracking system (IRIS eye tracker; Bablock-bscope, sampling rate: $500 \mathrm{~Hz}$, resolution: $2 \mathrm{~min}$ arc). The time between the onset of the presentation of a pseudoword marked by the fixation point and the onset of the child's speech was measured and stored 
by the computer, and the time interval for each word was also stored.

\subsubsection{Experiment 2}

Experiment 2 investigated whether a child's ability to read a text improves if (1) the child only attempts to simultaneously recognize words or word segments consisting of no more letters than s/he is able to recognize simultaneously, (2) the amplitude of the reading saccades does not exceed the number of letters the child is able to recognize simultaneously, (3) the child fixates the word segments for the time interval needed (adequate fixation intervals), and (4) the time interval between the onset of the presentation of the word and the onset of the pronunciation of the word is sufficiently long (adequate speech- onset interval). To adopt such an adequate reading strategy, children were forced (1) to read only words or word segments not containing more letters than they were able to recognize simultaneously according to the result of experiment 1, (2) to fixate these words or word segments for the appropriate time interval, (3) to start to pronounce the words or word segments only after an appropriate time interval, and (4) to execute eye movements of an amplitude matching the length of the words or word segments whose letters could be recognized simultaneously (adequate reading saccades). A yellow fixation mark indicated the point within each word or word-segment to which the gaze was to be directed. A green cursor (segment cursor) to the left and/or right of the yellow fixation mark indicated which letters in the word segment were to be read simultaneously together with the letter at the location of the yellow fixation mark (Fig. 1). The yellow and green marks indicated which adjacent letters in a word or word segment should be read while the eyes fixated the yellow fixation mark. Whenever a word segment had been recognized, the next word segment to be read was shown. Then the yellow fixation mark moved to the middle character of the next word or word segment, indicating the goal of the saccade, i.e., the location where the gaze should be directed when the next word segment is read. A green cursor (segment cursor) to the left and/or to the right of the yellow fixation mark again showed which letters of the newly shown word or word segment were to be read while the eyes were directed to the shifted yellow fixation mark. The fixation mark and the segment cursor moved from word segment to word segment as they were to be read in succession.

The text to the right of a word or word segment to be read within a given time interval was not shown

\section{Lesen ist nicht}

Fig. 1. Experiment 2: To teach a reading strategy that compensates the causes of a child's reading disturbance, the reader is prevented from trying to recognize more letters simultaneously than s/he can. The reader is also prevented from executing saccades whose amplitude exceeds the number of letters that the child has recognized simultaneously. The reader is forced to fixate a word or word-segment sufficiently long and to look at the next word or word-segment only after speech-onset latencies that are no shorter than those needed by the reader. A yellow (light grey) and green (dark grey) cursor showed the letters to be recognized simultaneously. The yellow fixation mark (light grey) indicated the letter to which the gaze was to be directed. The green cursor (segment cursor) (dark grey) showed the letters to be recognized together with the letter marked by the yellow cursor. The word "nicht" is marked by both the yellow and the green cursor until this word has been read correctly. The next word segment to be recognized will only be shown after the word "nicht" had been read correctly. Then the yellow fixation mark moves to the middle character of the next word segment, indicating where the gaze should be directed after the word "nicht" had been read correctly. The green cursor also shifts to the next word segment indicating the letters to be recognized simultaneously together with the letter marked by the yellow cursor.

on the monitor to prevent the child from terminating fixation of a word or word segment by exerting a premature saccade before the necessary fixation time had elapsed. The next word segment to be read was shown only after the previous word segment had been recognized. If premature saccades are a cause for the reading deficiency, reading is expected to normalize if premature saccades are prevented.

An acoustic signal was presented at a given time interval after the yellow mark which indicated the letter to be fixated, and the green cursor to the left and/or to the right of the yellow cursor were moved to the new segment to be read to prolong the time interval between the beginning of the fixation of the word or word segment to be read and the onset of its pronunciation. The time interval that the new word or word segment to which the yellow cursor and the green curser were shifted had to be fixated was at least as long as the mean of the time intervals a word or word segment had to be fixated in experiment 1 for the child to recognize at least 19 out of 20 pseudowords correctly. After this time interval had elapsed, an acoustic signal indicated that the child was allowed to pronounce the word or word segment. Then the yellow and green cursors shifted to the next word or word segment to be read. An acoustic signal again indicated when the subject was allowed to pronounce the word or word segment. Each child thus learned the appropriate reading strategy. 
The words were black (luminance: about $5 \mathrm{~cd} / \mathrm{m}^{2}$; height: about $15 \mathrm{~mm}$; space between letters: about $4 \mathrm{~mm}$ ) on a background of $60 \mathrm{~cd} / \mathrm{m}^{2}$. Fixation of the word segments and saccadic eye movements were recorded using an infrared eye-tracking system (IRIS eye tracker; sampling rate: $500 \mathrm{~Hz}$ ). Eye movements were monitored on line, stored, and analyzed on line and off line. The time between the onset of the presentation of the word segment marked with the fixation point and the segment cursor and the onset of the child's speech was measured and stored by the computer.

\subsubsection{Retest}

After having learned and practiced this reading strategy for 20 minutes, the children were asked to read the remaining part of the ZRT. This half of the text was presented in the same way as the other half of the test had been presented before the training session, i. e. on printed cards. No part of the text was omitted, and no cursor or sound that could aid the execution of the new reading strategy was presented. The children did not get any feedback about their performance.

\subsection{Statistics}

The difference in the rates of the correctly and incorrectly read pseudo-words in experiment 1 was tested for significance using the Kruskal-Wallis test. The reading performance before and after therapy was tested for significance using the Wilcoxon test. The effect of the reading therapy was calculated using the Hedges-g effect size (Borenstein et al., 2009).

\section{Results}

\subsection{Immediate improvement of the ability to read pseudowords}

The result of experiment 1 shows that the location to which the eyes should be directed within a word to be read, the number of letters to be read simultaneously, the time that a word should be fixated, and the instant when the subject should start to pronounce the word can be adjusted so that even dyslexic subjects are able to read $95 \%$ of pseudowords correctly.

As long as the pseudowords were not presented in such a way that they could be read correctly, and the subjects made reading mistakes; incorrectly read letters occurred at all locations in a pseudoword.
Figure 1 shows that the rate of misread letters depended on the location of the letter within a word. The rate of incorrectly read letters increased from the first letter at the beginning of a word to the letter that was to the right of the fixation point (Fig. 2). This increase did not depend on the length of the pseudoword or whether a letter was flanked on the left, on the right, or on both sides by other letters. This was true for reading mistakes, such as the omission of letters, incorrect replacement of letters by letters that were not present in the pseudoword, changes in the position of letters in a word, and increasing the length of the word by adding new letters. The rate of misread letters to the right of the fixation point exceeded the rate of misread letters at the fixation point. Letters to the left of the fixation point were less often misread than those at the fixation point. This was independent of the length of the pseudoword.

In most children the rate of reading mistakes did not decrease below 5\% until the number of letters in a pseudoword was reduced and/or the subjects started pronouncing the word to be read later. The results of this experiment are summarized in Table 1. Children with reading disturbances differed considerably in the number of letters they were able to recognize simultaneously and the fixation time needed to recognize a sequence of letters simultaneously. $25 \%$ of the children were able to recognize 5 or 6 letters simultaneously within a fixation interval of $350 \mathrm{~ms}$. $39 \%$ of the children who were only able to recognize 3 or 4 letters simultaneously recognized these 3 or 4 letters within $350 \mathrm{~ms}$. Speech-onset latency was almost the same in children who were able to recognize 3, 5, or 6 letters simultaneously. Only children who recognized 4 letters simultaneously had significantly shorter speech-onset latencies (KruskalWallis-Test: $p<0.00001$ ). If fixation times were too short and/or the subjects tried to read too many letters in pseudowords simultaneously, the rate of mistakes increased to such an extent that all pseudowords in a list were read incorrectly.

\subsection{Immediate improvement in reading ability after changing the reading strategy}

The children who read the first or the second half of the ZRT before the reading training read a mean $14.8 \%$ of the words incorrectly $(S D=6.14 \%)$. When these children read the remaining half of the Zuercher Reading Test after the training, a mean of only $6.12 \%(\mathrm{SD}=3.52 \%)$ of the words was read incorrectly. This corresponds to a $58.87 \%$ decrease 


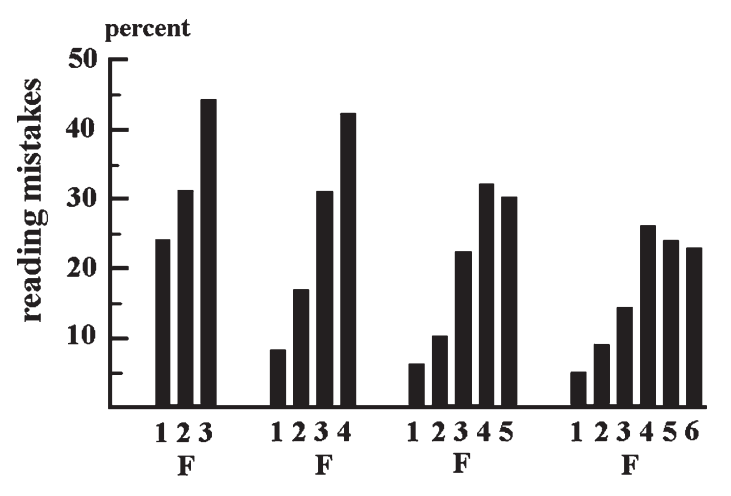

Fig. 2. Experiment 1: Each column represents the percentage of errors a person made when a letter was at a certain position within a 3-, 4-, 5-, or 6-letter pseudoword. The words were displayed for between 250 and $500 \mathrm{~ms}$. F: letter that was at the fixation point. 1: first letter at the beginning of the word; 2 : second letter from left; 3 : third letter from left, etc. Reading of a word was considered an error if: a letter was read incorrectly, omitted, the location of the letter was swapped, or if a letter was read that did not appear in the word. In 3-letter pseudowords, the differences between the rates of letters at positions 1, 2, 3 read incorrectly did not reach significance (Kruskal-Wallis Test: $p>0.05$ ). In 4-, 5-, and 6-letter pseudowords, the rates of letters at different positions within a word read incorrectly differed significantly (Kruskal-Wallis Test: 4-letter pseudowords: 3 rd versus 4 th letter and 2 nd versus 4 th letter: $p<0.0006$; 5-letter pseudowords: first letter versus 3rd: $p<0.273$, first letter versus 4th and 5th letter: $p<0.0071$, 2nd versus 3rd and 4th letter: $p<0.021$; 6-letter pseudowords: first versus 4th, 5 th and 6th letter $p<0.004$, 2nd versus 5th, 3rd versus 4th and 5th letter: $p<0.05)$.

in words read incorrectly within a single session. The difference between the number of reading mistakes before and after the training was highly significant
(Wicoxon Test: $p<0.00001$ ). The calculation of the effect strength resulted in a Hedges-g effect size of 1.734 , indicating a very strong effect of the reading training. 36 children in the therapy group read $20 \%$ to $30 \%$ of the words incorrectly before the therapy. In 17 children, the number of errors decreased by 50 to $70 \%$, and the error rate decreased by 70 to $90 \%$ in 8 children.

In the control group, there was no significant difference between the percentage of incorrectly read words when reading one half of the ZRT first and the remaining half afterwards. When reading one half of this test first, a mean of $12.47 \%(\mathrm{SD}=6.39 \%)$ of the words were read incorrectly. When the controls read the remaining half of this test later on, $13.20 \%(\mathrm{SD}=7.02 \%)$ of the words were read incorrectly. This difference was not significant (Wilcoxon Test: $p>=0.1$ ). The Hedges-g-value was 0.109 for the conrol group, indicating that there was no effect.

In the control group, the time needed to initially read one half of the test $(x=238.76 \mathrm{sec}$; $\mathrm{SD}=152.04 \mathrm{sec}$ ) also did not significantly differ (Wilcoxon Test: $p>0.8$ ) from the time needed to read the remaining half of the test later $(x=237.66 \mathrm{sec}$; $\mathrm{SD}=137.47 \mathrm{sec})$. The subjects in the training group had learned to prolong their fixation times and/or speech-onset times according to the fixation times and speech-onset times that they needed for correct reading. As a result, the time required to read one half of the test was significantly lengthened (Wilcoxon-test: $p<0.00001$ ). Before the training, the

\section{Table 1}

Shows the number of letters, fixation times, and mean speech-onset times of 100 dyslexic children when the number of letters, fixation time, and speech onset-time were altered until at least $95 \%$ of the pseudowords were read correctly. Twenty-six percent of the children were only able to read 3 letters simultaneously (second column from left and second row from below). The speech-onset latency in these children was a mean of $1624.09 \mathrm{~ms}(\mathrm{SD}=893.57 \mathrm{~ms})$ (bottom row). 15 children needed a fixation interval of $250 \mathrm{~ms}$. Four letters were recognized simultaneously by 45 children (second column from left and bottom row). Only 20 children were able to recognize the 4 letters simultaneously in $250 \mathrm{~ms}$ (third column from left and second row from above). The mean of the speech-onset latency was $1316.44 \mathrm{~ms}(\mathrm{SD}=712.14 \mathrm{~ms})$ (third column from left and bottom row). The ability to recognize 5 letters simultaneously was observed in 22 children (forth column from left and second row from below). Only 14 children needed a fixation interval of $250 \mathrm{~ms}$ (forth column from left and second row from above). The mean speech-onset latency was $1670.06 \mathrm{~ms}$ ( $\mathrm{SD}=641.83 \mathrm{~ms}$ ) (forth column from left and bottom row). Only 7 children were able to recognize all the letters in a 6-letter pseudoword simultaneously (fifth column from left and second row from below). Five children needed no more than $250 \mathrm{~ms}$ to recognize these pseudowords (fifth column from left and second row from above). Their speech-onset latency was $1658.83 \mathrm{~ms}(\mathrm{SD}=762.23)$ (fifth column from left and bottom row)

\begin{tabular}{|c|c|c|c|c|}
\hline Length of Recognized Pseudowords (Number of Letters) & 3 letters & 4 letters & 5 letters & 6 letters \\
\hline Number of Patients who Recognized Pseudowords in $250 \mathrm{~ms}$ & 15 & 20 & 14 & 5 \\
\hline Number of Patients who Recognized Pseudowords in $300 \mathrm{~ms}$ & 2 & 0 & 0 & 0 \\
\hline Number of Patients who Recognized Pseudowords in $350 \mathrm{~ms}$ & 0 & 2 & 6 & 0 \\
\hline Number of Patients who Recognized Pseudowords in $400 \mathrm{~ms}$ & 6 & 15 & 1 & 2 \\
\hline Number of Patients who Recognized Pseudowords in $450 \mathrm{~ms}$ & 3 & 7 & 1 & 0 \\
\hline Number of Patients who Recognized Pseudowords in $500 \mathrm{~ms}$ & 0 & 1 & 0 & 0 \\
\hline$\Sigma$ Number of Patients who Recognized Pseudowords & 26 & 45 & 22 & 7 \\
\hline Mean Speech Onset Latency for Recognized Pseudowords & $\begin{array}{l}\mathrm{x}=1624.09 \mathrm{~ms} \\
\mathrm{SD}=893.57 \mathrm{~ms}\end{array}$ & $\begin{array}{l}x=1316.44 \mathrm{~ms} \\
\mathrm{SD}=712.14 \mathrm{~ms}\end{array}$ & $\begin{array}{l}x=1670.06 \mathrm{~ms} \\
S D=641.83 \mathrm{~ms}\end{array}$ & $\begin{array}{c}\mathrm{x}=1658.83 \mathrm{~ms} \\
\mathrm{SD}=762.23 \mathrm{~ms}\end{array}$ \\
\hline
\end{tabular}


mean reading time was $197.68 \mathrm{sec}(\mathrm{SD}=93.96 \mathrm{sec})$; after the training, the mean reading time for the remaining half of the test was $350.58 \mathrm{sec}$ $(\mathrm{SD}=149.23 \mathrm{sec})$.

There was also a correlation between the number of letters the children $(n=100)$ were able to recognize simultaneously in experiment 1 (when pseudowords were presented so that children could recognize them correctly) and the number of reading errors the children made when they read the text of the ZRT without having learned the new reading strategy. Children who were not able to recognize more than 3 letters simultaneously when reading pseudowords in experiment 1 (when pseudowords were presented so that the children could recognize them correctly), made significantly more reading errors in the ZRT (reading errors in the ZRT: $x=19.73 \%$; $\mathrm{SD}=7.9 \%$ ) than children who were able to recognize 4 letters in experiment 1 (reading errors in the ZRT: $x=12.53 \%$; $\mathrm{SD}=5.13 \%$ ) (Kruskal-Wallis Test: $p=0.038$ ). Subjects who were able to recognize 5 letters simultaneously in experiment 1 made fewer reading errors in the ZRT ( $x=11.01 \%$; $\mathrm{SD}=5.42 \%)$ than subjects who were able to recognize only 3 letters simultaneously (Kruskal-Wallis Test: $p=0.02$ ). Subjects who were able to recognize 6 letters simultaneously in experiment 1 made also fewer reading errors in the ZRT: $x=7.57 \%, \mathrm{SD}=2.47 \%$ ) than subjects who were only able to recognize 3 letters simultaneously (Kruskal-Wallis Test: $p=0.001$ ).

\section{Discussion}

Experiments 1 and 2 investigated whether it is possible to establish conditions under which poor readers can improve their reading ability. Therefore, the computer presented words under conditions which enabled even subjects who suffered from a severe reading disability to read at least $95 \%$ of the words correctly. In all subjects $(n=100)$ who participated in experiment 1 , correct fixation, an extension of the fixation time, a reduced number of letters in the word to be read, and delayed pronounciation of the word resulted in $95 \%$ of the words being read correctly. In experiment 2 , the computer forced the children in the therapy group to fixate the words at the correct location and for a sufficiently long time interval, to exert correct eye movements, and not to start to pronounce the words too early when reading a normal German text on a monitor. When the subjects transferred the reading strategy to reading a printed text, reading mistakes dropped by $58.87 \%$ within one single session. During the therapy all influences on the reading performance were under the control of the experimenter.

Studies of therapy effects widely accept that a retest should be carried out a certain time interval after starting the therapy. This applies only if influences that can affect the result and are outside the control of the examiner can be ruled out. Children, who have been undergone reading therapy for several months are not under the constant control of the examiner, may have been exposed to numerous uncontrolled influences at home and in school, which can have an impact on reading. As a retest carried out after weeks or months is methodologically flawed for these reasons, it was not part of the present experiment.

Experiments have shown that reading mistakes may have various causes. Reading presupposes many different abilities, and a disturbance of any of these abilities may cause a severe reading impairment.

\subsection{The role of appropriate fixation in reading}

The ability to focus one's gaze on a word or word segment to be read so that it is projected onto the foveal and parafoveal region of the retina where there is sufficient visual acuity is among the basic skills required for correct reading (Rayner 1975). This means that appropriate fixation of the word or word segment to be read is a necessary (but not sufficient) condition for reading. Visual acuity drops sharply outside the foveal and parafoveal region (Kerr 1971). Ideally, a word or word segment to be read is fixated approximately in the middle of the word or word segment. Then the largest number of letters is displayed in the area of highest visual acuity. If a person fixates a word or word segment at its beginning or its end, fewer letters are displayed in the area of highest visual acuity, and some letters are located in an area of lower visual acuity. Poor reading that is caused by incorrect fixation of the words to be read may improve when the subject is forced to correctly fixate each word to be read. Therefore, the subjects were forced to fixate the words to be read approximately in the middle, and fixation was controlled throughout the experiments.

\subsection{The role of simultaneous recognition of letters and fixation time in reading}

To read fluently, the reader must not read letter by letter, but several letters simultaneously. S/he must be able to simultaneously recognize several letters that 
appear in the area of sufficiently high visual acuity within a short time interval. Experiment 1 investigated how many letters a word can contain so that all letters in this word can be read simultaneously, i. e. when the eyes were constantly directed to the word without executing an eye movement. The result of experiment 1 reveals that this ability differs considerably among subjects. Table 1 shows that 9 subjects could not recognize more than 3 letters when they were presented for less than $400 \mathrm{~ms}$, and 23 subjects could not recognize more than 4 letters when they were presented for less than $400 \mathrm{~ms}$. In contrast, 5 subjects could simultaneously recognize 6 letters during a fixation time of 250 milliseconds. Neuropsychological studies on brain-damaged patients have shown that the ability to recognize several items simultaneously is a dissociated brain capacity independent of other cerebral capacities. If a person tries to recognize more letters than $\mathrm{s} / \mathrm{he}$ is able to recognize simultaneously, the recognition process will be flawed, and reading errors will occur. To avoid reading mistakes, the subjects were taught not to try to recognize more letters simultaneously than they were able.

Tachystoscopic studies (Eagle 1959; Sperling 1960) have shown that whether complex visual stimuli are recognized or not depends largely on the time that these visual stimuli are projected onto the retina. Too short a fixation time limits the ability to recognize several letters simultaneously. To prevent reading mistakes, experiment 1 also examined how long a subject needs to fixate a word of a certain length to recognize it correctly. Experiment 1 showed that a prolongation of fixation times increased the ability to simultaneously recognize a sequence of letters. The ability to recognize several letters simultaneously improved only up to a certain fixation time, which was specific for each individual subject. If the fixation time was extended beyond the specific duration, the ability to recognize several letters at the same time no longer improved.

A reduced ability to recognize a succession of letters simultaneously cannot only be attributed to a narrowing of the field of attention (Godijn \& Theeuwes 2003; Gersch et al., 2004; Baldauf \& Deubel 2008). Figure 1 shows a gradient in the frequency of reading errors which increased from left to right. More mistakes were made when the letters were at the fixation point than when letters were to its left. The subjects could extent their field of attention sufficiently to the left and to the right of the fixation point within a long fixation time of more than $400 \mathrm{~ms}$.
The finding that numerous subjects could not simultaneously recognize more than 3 or 4 letters even within a fixation time of more than $400 \mathrm{~ms}$ indicates that they had a diminished ability to simultaneously recognize letters within a field of attention. This correlates with reports about brain-damaged patients who were able to detect an object or a spot of light in either visual field when it was presented alone. Only one object was detected when two objects were presented at the same time (Balint, 1909; Poppelreuther 1917; Faust, 1947; Critchley, 1949; Denny-Brown et al., 1952; Luria, 1959; Posner et al., 1982). It has been shown that the simultaneous perception of several items is an independent (dissociated) visual performance that can be selectively impaired (Poppelreuter, 1917; Luria, 1959). Poor readers' reduced ability to visually process multiple letters simultaneously may also be an independent disturbance (Werth 2001).

\subsection{The role of saccades in reading therapy}

Saccadic eye movements during reading must be adjusted to the ability to recognize a sequence of letters simultaneously. If a person has recognized all the letters of a word or a word segment, a saccade to the next word or word segment to be read must be executed. The brain must select the target of this saccade, program an eye movement to this gaze target, and perform the correct saccadic eye movement (Olsen et al. 1983; Underwood et al. 1990; Morris et al. 1990; Kowler et al. 1995). The amplitude of this saccade depends on the number of letters a reader can recognize simultaneously. For example, if a reader can recognize five letters simultaneously, but carries out a saccade to a visual target which is ten letters to the right of the previously fixated letter, s/he can only read two letters to the left and two letters to the right of the letter that is the new visual target. However, s/he cannot recognize the five letters located between the letters to the right of the word or word segment previously recognized and the letters to the left of the letter which is fixated after the saccade has been completed. This reader can only recognize all letters of the sequence of words or word segments if $\mathrm{s} / \mathrm{he}$ executes a saccade of five letters. Only then is there a gapless transition between the five letters of the word or word segment to be read after a saccade has been completed and the letters of the word or word segment previously read. In Experiment 2, the subjects learned to perform eye movements while 
reading which were not greater than the number of letters they could simultaneously recognize.

\subsection{Are reading mistakes due to unusual foveal or parafoveal processing?}

Reading mistakes may be due to unusual foveal or parafoveal processing or the fact that the letters to be recognized are flanked by other letters (Geiger \& Lettvin 1987, Atkinson 1997; Lorusso et al., 2004). This phenomenon, known as "lateral masking" or "crowding effect", occurs outside the fovea and is particularly pronounced in the peripheral visual field. The result of experiment 1 showed that leaving out letters, replacing letters, or incorrectly adding letters occurred at all positions within the words. Reading mistakes occurred irrespective of whether a letter within a word was presented in the fovea or up to 3 letters (i. e. 6 degrees of visual angle) from the fovea. Therefore, reading mistakes are not due to poor processing of letters outside the fovea.

\subsection{Is the effect of training due to slow reading ?}

One might assume that slow reading is already sufficient to significantly improve reading performance. However, reading slowly is not sufficient to reduce reading mistakes. If, for example, reading becomes slower because a patient prolongs fixation time, but tries to recognize too many letters simultaneously, reading mistakes will not necessarily decrease. Experiment 1 showed that longer fixation intervals do not always improve simultaneous recognition. Reading only improves (1) if the fixation time is adequate, (2) if the reader only tries to recognize a limited number of letters, (3) if his/her speech onset time is adequate, and (4) if the reader executes saccades with amplitudes which do not exceed the number of letters $\mathrm{s} / \mathrm{he}$ is able to recognize simultaneously.

In all patients the same abilities were investigated but the therapies were not the same. As Table 1 shows, some subjects needed longer, some shorter fixation times, some were able to process more letters simultaneously than others at a given fixation interval, some needed longer speech onset times than others. The therapy differed with regard to the number of letters the children were to process simultaneously (and consequently with regard to the amplitude of the saccades to be made), with regard to the fixation time, and the speech onset time.

\subsection{The role of syllable segmentation in reading therapy}

The Hedges g-value of 1,734 revealed that the reading training performed in Experiment 2 was highly effective, as a value of 0.8 is already interpreted as a strong effect. There was, however, no effect in the control group. In a metastudy about the effectiveness of reading therapy in German children, none of the treatments reached an effectiveness of more than $g=0.7$, even if the training lasted 20 weeks (Ise et al., 2012). In a metastudy about reading therapy for poor reading English speaking children, Galuschka et al. (2014) found that no therapy reached a similar effectiveness as the present study. The highest effect size (0.8) of a reading training with German children was reached in a recent study by Müller et al. (2017) who used a syllable segmentation approach. A similar syllable segmentation approach that Bhattacharya and Ehri (2004) used with adolescents was very effective, but cannot be compared to the results obtained with children. The advantage of syllable segmentation to improve reading performance has also been proposed by other authors (Duncan \& Seymour 2003; Bhattacharya 2006; Knight-McKenna 2008).

The results of Müller et al. (2017) and Bhattacharya and Ehri (2004) are in agreement with the results of experiments 1 and 2 of the present study. The segmentation of words is one of several features of the reading therapy proposed by Werth (2001). It has proven to be effective for the treatment of reading disorders (Werth 2006; Klische 2007) and was used in experiment 2 of the present study. As the studies of Müller et al. (2017) and Bhattacharya and Ehri (2004) show, the segmentation of words may already be sufficient to improve reading skills to a certain extent, but this is not sufficient for adequate reading in all children. The size of the segments and the fixation time must be adapted to the individual reader's ability, and the amplitude of the saccades must be adapted to the size of the words or word segments that a reader can recognize simultaneously.

Segmentation on the level of syllables is also not appropriate as syllables often consist of more letters than poor readers can recognize simultaneously. Therefore, it must always first be investigated how many letters readers can recognize simultaneously. The segments in which the words to be read should be subdivided, must not contain more letters than the reader can recognize simultaneously. Experiment 1 and 2 also show that the fixation time and phoneme retrieval time are important aspects of the reading 
process, which should not be neglected in the treatment of reading problems.

\subsection{Is improvement in reading ability due to the mental representation of syllables?}

The results of experiments 1 and 2 show, that improvement in reading ability cannot be interpreted as a consequence of the mental representation of syllables and words that consist of these mentally represented syllables. The improvement in reading performance cannot be achieved by intensive training in syllable reading and the resulting better "mental representation" of these syllables (Müller et al., 2017). Experiments 1 and 2 show that the "mental representation" of syllables does not play a decisive role in reading training. This is because no syllabic recognition was practiced during the reading training. Reading performance improved solely due to a reduction in segment size, an increase in fixation time, an extension of phonemic retrieval time, and an adaptation of the amplitudes of the saccades to the size of the segments. These were sufficient conditions to improve reading performance. This was regardless of whether the segment was a syllable.

\subsection{Is improvement in reading ability due to Phonological Awareness}

The assumption of the proponents of "Phonological Awareness" that a training of awareness of the phonological structure of words improves reading performance was also not confirmed. Phonological awareness training includes the detection and distinction of speech sounds, syllable segmentation, syllable detection, and rhyme detection (Bradley \& Bryant 1983; Lundberg et al., 1988; Wagner et al., 1993; McBride-Chang 1995; Frost 1998).

The concept of „Phonological Awareness“ has already been criticized on psycholinguistic grounds (Valtin 2010, 2012), and the effect of the Phonological Awareness training on reading and spelling performance has been questioned (May \& Okwumo 1999; Krashen 2004). The results of experiments 1 and 2 do not indicate that Phonological Awareness training can help to improve reading performance. Only syllables and phonem segmentation, that is a feature of Phonological Awareness training, is suitable to improve the ability to split words into segments. When reading performance improved somewhat after Phonological Awareness training, this may have been because the training of syllable recognition caused a tendency to split the text into segments and to read in segments. However, the individual ability of simultaneous recognition, the saccade amplitudes (determined by the length of the segments), the individual fixation times, and the different retrieval times were not taken into account in Phonological Awareness training.

\subsection{Are traditional reading tests adequate?}

The results of the experiments described above show that reading tests which investigate how many mistakes, and what kind of mistakes a reader makes and the time s/he needs to read a text are insufficient tools for the diagnosis of dyslexia. Such tests ignore whether the reader fixates the words or word segments to be read at an appropriate location, whether the reader's ability to process letters simultaneously is reduced, whether the amplitudes of the saccades correspond to the number of letters that can be recognized simultaneously, whether the reader needs a long fixation time to process a given number of letters, and how much time a reader needs from the beginning of the fixation until $\mathrm{s} / \mathrm{he}$ is able to pronounce a word correctly.

\subsection{Is the definition of "dyslexia" adequate?}

Reading disability is termed "dyslexia" if it is much (about two standard-deviations) below other cognitive abilities according to the intelligence quotient (IQ) (Stein 2001; Lyon et al., 2003; Fletcher 2009). A definition of "dyslexia" with regard to the intelligence quotient is, however, questionable. If a reader with a low IQ has poor reading abilities due to too short a fixation time, and/or if s/he tries to recognize more letters simultaneously than s/he is able to, and/or if his/her speech onset time is too short, and/or if the reader executes saccades with amplitudes which exceed the number of letters $\mathrm{s} / \mathrm{he}$ is able to recognize simultaneously s/he suffers from the same kind of dyslexia as a reader with a high IQ with the same reading disability. Therefore, the diagnosis of "dyslexia" should be made irrespective of IQ.

\subsection{The neurobiological basis of dyslexia}

The results of experiments 1 and 2 are in agreement with contemporary findings and theories about the neurobiological basis of dyslexia. Any neurobiological impairment that can reduce the ability to recognize a succession of letters simultaneously, to 
extend the field of attention sufficiently to cover all letters of a word or word-segment to be read, to keep the eyes directed to the center of a word or word-segment to be read until the word has been recognized, to execute saccades that match the number of letters that can be read simultaneously, to retrieve phonems that correspond the letters of a word within an adequate time interval, to pronounce the word or word-segment correctly, and to decode the meaning of words and sentences may cause a reading disability. This includes a magnocellular deficit (Stein 2001, 2012, Stein \& Walsh 1997), a disruption of left hemisphere posterior brain systems in dyslexic readers, a dysfunction of the left occipitotemporal area (Shaywitz 2005, 2008), abnormalities in the left temporo-parietal cortex, middle frontal gyrus, the left inferior frontal gyrus superior occipital gyrus, parieto-occipital regions, the left ventral occipitotemporal and middle temporal area including the supramarginal gyrus (Brunswick et al., 1999; Maisog et al., 2008; Chang et al., 2010; Richlan et al., 2011; Linkersdorfer et al., 2012; Vandermosten et al., 2012), in left frontoparietal (Cao et al., 2008; Quaglino et al., 2008), temporoparietal, and ventral occitititemporal fiber connections (van der Mark et al., 2011), in the arcuate fasciculus, superior longitudinal fasciculus, inferior fronto-occipital fasciculus, optic radiation, and the corpus callosum (Frye et al., 2011).

\section{References}

Ashkenazi, S., Black, J.M., Abrams, D.A., Hoeft, F. \& Menon, V. (2013). Neurobiological Underpinnings of Math and Reading Learning Disabilities. Journal of Learning Disabilities, 46, 549-569.

Atkinson, J. (1991). Review of human visual development: Crowding and dyslexia. Vision and Visual Dyslexia, 13, 44-57.

Baldauf, D. \& Deubel, H. (2008). Properties of attentional selection during the preparation of sequential saccades. Experimental Brain Research, 184, 411-425.

Balint, R. (1919). Seelenlähmung des "Schauens", optische Ataxie, räumliche Störung der Aufmerksamkeit. Monatsschrift für Psychiatrie und Neurologie, 25, 51-81.

Bhattacharya, A. \& Ehri, L.C. (2004). Graphosyllabic analysis helps adolescent struggling readers read and spell words. Journal of Learning Disabilities, 37, 331-48.

Biscaldi, M., Fischer, B. \& Hartnegg, K. (2000). Voluntary saccadic control in dyslexia. Perception, 29, 509-521.

Black. J.M., Xia, Z. \& Hoeft, F. (2017). Neurobiological bases of reading disorder part II: The importance of developmental considerations in typical and atypical reading. https://doi.org/10.1111/lnc3.12252.
Borenstein, M., Hedges, L.V., Higgins, J.P.T. \& Rothstein, H.R. (2009). Introduction to Metaanalysis. Wiley, Chichester.

Bos, W., Bremerich-Vos, A., Tarelli, I. \& Valtin, R. (2012) Lesekompetenzen im internationalen Vergleich. In: W Bos, I Tarelli, A Bremerich-Vos, K Schwippert (eds): IGLU 2011. Lesekompetenzen von Grundschulkindern in Deutschland im internationalen Vergleich. Münster: Waxmann, pp. 91-136.

Bradley, L., \& Bryant, P. (1983). Categorizing sounds and learning to read: A causal connection. Nature, 301, 419-421.

Brunswick, N., McCrory, E., Price, C.J., Frith, C.D. \& Frith, U. (1999). Explicit and implicit processing of words and pseudowords by adult developmental dyslexiscs - a search for Wernicke's Wortschatz? Brain, 122, 1901-1917.

Buchholz, J. \& Davis, A.A. (2005). Adults with dyslexia demonstrate space-based and object-based covert attention deficits: Shifting attention to the periphery and shifting attention between objects in the left visual field. Brain and Cognition, $57,30-34$.

Cao, F., Bitan, T. \& Booth, J.R. (2008). Effective brain connectivity in children with reading difficulties during phonological processing. Brain and Language, 107, 91-101.

Chang, E.F., Rieger, J.W., Johnson, K., Berger, M.S., Barbaro, N.M., \& Knight, R.T. (2010). Categorical speech representation in human superior temporal gyrus. Nature Neuroscience, $13,1428-1432$.

Costanzo, F., Varuzza, C., Rossi, S., Sdoia, S., Varvara, P., Oliveri, M., Giacomo, K., Vicari, S. \& Menghini, D. (2016), Evidence for reading improvement following tDCS treatment in children and adolescents with Dyslexia. Restorative Neurology and Neuroscience 34, 215-226.

Critchley. M. (1949). The phenomenon of tactile inattention with spezial reference to parietal lesions. Brain, 72, 538-561.

Denny-Brown, D., Meyer, J.S. \& Horenstein, S. (1952). The significance of perceptual rivalry resultung from parietal lesion. Brain, 75, 433-471.

Duncan, L.G. \& Seymour, P.H.K. (2003). How do children read multisyllabic words? Some preliminary observations. Journal of Research in Reading, 26, 101-120.

Eagle, M. (1959). The effects of subliminal stimuli of aggressive content upon conscious cognition. Journal of Personality, 27, 578-600.

Farah, M., Stowe, R.M. \& Levinson, K.L. (1996). Pholological dyslexia Loss of a reading specific component of cognitive architecture? Cognitive Neuropsychology, 13, 849-868.

Faust, C. (1947). Über Gestaltzerfall als Symptom des parietookzipitalen Übergangsgebietes bei doppelseitiger Verletzung nach Hirnschuss. Nerverarzt, 18, 103-115.

Fischer, B. \& Hartnegg, K. (2000). Effects of visual training on saccade control in dyslexia. Perception, 29, 531-542.

Fletcher, J.M. (2009). Dyslexia: The evolution of a scientific concept. Journal of the International Neuropsychological Society, 15, 501-508.

Frost, R. (1998). Toward a strong phonological theory of visual word recognition: True issues and false trails. Psychological Bulletin, 123, 71-99.

Frye, R.E., Liederman, J., Hasan, K.M., Lincoln, A., Malmberg, B., McLean, J., 3rd \& Papanicolaou A. (2011). Diffusion tensor quantification of the relations between microstructural and 
macrostructural indices of white matter and reading. Human Brain Mapping, 32, 1220-1235.

Galuschka, K., Ise, E., Krick, K. \& Schulte-Körne G. (2014). Effectiveness of Treatment Approaches for Children and Adolescents with Reading Disabilities: A Meta-Analysis of Randomized Controlled Trials. PLoS, https://doi.org/10.1371/journal.pone.0089900.

Geiger, G. \& Lettvin, J.Y. (1987). Peripheral vision in persons with dyslexia. New England Journal of Medicine, 316, 1238-1243.

Gersch, T.M., Kowler, E. \& Dosher, B. (2004). Dynamic allocation of visual attention during the execution of sequences of saccades. Vision Research, 44, 1469-1483.

Godijn, R. \& Theeuwes, J. (2003). Prallel allocation of attention prior to the execution of saccade sequences. Journal of Experimental Psychology: Human Perception and Performance, 29, 882-896.

Ise, B., Engel, R.R. \& Schulte-Körne, G. (2012). Was hilft bei Lese-Rechtschreibstörung? Ergebnisse einer Metaanalyse zur Wirksamkeit deutschsprachiger Förderansätze. Kindheit und Entwicklung, 21, 122-136.

Katusic, S.K., Colligan, R.C., Barbaresi, W.J., Schaid, D.J. \& Jacobsen, S.J. (2001). Incidence of reading disability in a population-based birth cohort, 1976-1982. Rochester, Minnesota Mayo Clinic Proceedings, 76, 1081-1092.

Kerr, J.L. (1971). Visual resolution in the periphery. Perception \& Psychophysics, 9, 375-378.

King, W.M., Lombardino, L.J., Crandell, C.C. \& Leonard, C.M. (2003). Comorbid auditory processing disorder in developmental dyslexia. Ear and Hearing, 24, 448-456.

King, W.M., Giess, S.A. \& Lombardino, L.J. (2007). Subtyping of children with developmental dyslexia via bootstrap aggregated clustering and the gap statistic: Comparison with the double-deficithypothesis. International Journal of Language Communication Disorders, 42, 77-95.

Klische, A. (2007). Leseschwächen gezielt beheben. Individuelle Diagnose und Therapie mit dem Programm celeco. Marburg: Tectum.

Knight-McKenna, M. (2008). Syllable types. A strategy for reading multisyllabic words. Teaching Exceptional Children, 40, 1824

Kowler, E., Anderson, E., Dosher, B. \& Blaser, E. (1995). The role of attention in programming saccades. Vision Research, 35, 1897-1916.

Krashen, S. (2004). False claims about literacy development. Educational Leadership, 61, 18-21.

Linkersdorfer, J., Lonnemann, J., Lindberg, S., Hasselhorn, M., \& Fiebach, C.J. (2012). Grey matter alterations co-localize with functional abnormalities in developmental dyslexia: An ALE meta-analysis. PLoS One, 7, e43122. https://doi.org/10.1371/journal.pone.0043122.

Lorusso, M.L., Facoetti, A., Pesenti, S., Cattaneo, C., Molteni, M. \& Geiger, G. (2004). Wider recognition in peripheral vision common to different subtypes of dyslexia. Vision Research, $44,2413-24$

Lundberg, I., Frost, J. \& Petersen, O. (1988). Effects of an extensive training program for stimulating phonological awareness in preschool children. Reading Research Quarterly, 23, 263284.
Luria, A.R. (1959). Disorders of simultaneous perception " in a case of bilateral occipito-parietal brain injury. Brain, 82, 437-449.

Lyon, G.R., Shaywitz, S.E. \& Shaywitz, B.A. (2003). A Definition of Dyslexia. Annals of Dyslexia, 53, 1-14.

May, P. \& Okwumo, S. (1999). Effekte vorschulischer Trainings zur Schriftanbahnung auf das Rechtschreiblernen im ersten Schuljahr. www.unihamburg.de/psycholo/frames/ projekte/PLUS/May_Okwumo_99_Eff_VS_Train. 16.6.2009

Maisog, J.M., Einbinder, E.R., Flowers, D.L., Turkeltaub, P.E. \& Eden, G.F. (2008). A meta-analysis of functional neuroimaging studies of dyslexia. Annals of the New York Academy of Sciences, 1145, 237-259.

McBride-Chang, C. (1995). What is phonological awareness? Journal of Educational Psychology, 87, 179-192.

Morris, R.K., Rayner, K. \& Pollatsek, A. (1990). Eye movement guidance in reading: The role of parafoveal letter and space information. Journal of Experimental Psychology Human Perception and Performance, 16, 228-281.

Moura, O., Pereira, M., Alfaiate, C., Fernandes, E., Fernandes, B., Nogueira, S. \& Simoes, M.R. (2017). Neurocognitive functioning in children with developmental dyslexia and attention-deficit/hyperactivity disorder: Multiple deficits and diagnostic accuracy. Journal of Clinical and Experimental Neuropsychology, 39, 296-312.

Müller, B., Richter, T., Karageorgos, P., Krawietz. S. \& Ennemoser, M. (2017). Effects of a Syllable-Based Reading Intervention in Poor-Reading Fourth Graders. Frontiers in Psychology, 20, 2017, https://doi.org/10.3389/fpsyg.2017.01635.

Nagarajan, S., Mahnke, H., Salz, T., Tallal, P., Roberts, T. \& Merzenich, M.M. (1999). Cortical auditory signal processing in poor readers. Proceedings of the National Acadademy of Sciences USA, 96, 6483-6488.

Olsen, R.K., Kliegel, R. \& Davidson, B.J. (1983). Dyslexic and normal readers eye movements. The Journal of Experimental Psychology: Human Perception and Performance 9, 816-825.

Poppelreuter, W. (1917). Die psychischen Schädigungen durch Kopfschuß im Kriege 1914-1918. Bd. I. Die Störungen der niederen und höheren Sehleistungen durch Verletzungen des Okzipitalhirns. Leipzig, L. Voss.

Posner, M.I., Cohen, Y. \& Rafal, R.D. (1982). Neural systems control of spatial orientation. Philosophical Transactions of the Royal Society London B, 298, 187-198.

Quaglino, V., Bourdin, B., Czternasty, G., Vrignaud, P., Fall, S., Meyer, M.E. \& de Marco, G. (2008). Differences in effective connectivity between dyslexic children and normal readers during a pseudoword reading task: An fMRI study. Neurophysiologie Clinique/Clinical Neurophysiology, 38, 73-82.

Rayner, K. (1975). Parafoveal identification during a fixation in reading. Acta Psychologica, 39, 271-282.

Richlan, F., Kronbichler, M., \& Wimmer, H. (2011). Metaanalyzing brain dysfunctions in dyslexic children and adults. NeuroImage, 56, 1735-1742.

Roach, N.W. \& Hogben, J.H. (2004). Attentional modulation of visual processing in adult dyslexia: A spatial cuing deficit. Psychological Science, 15, 650-654.

Rutter, M., Caspi, A., Fergusson, D., Horwood, L.J., Goodman, R., Maughan, B., Moffitt, T.E., Meltzer, H. \& Carroll, J. (2004). Sex differences in developmental reading disability: 
New findings from 4 epidemiological studies. Journal of the American Medical Association, 291, 2007-2012.

Shaywitz, S.E., Shaywitz, B.A., Fletcher, J.M. \& Escobar, M.D. (1990). Prevalence of reading disability in boys and girls. Results of the Connecticut Longitudinal Study. Journal of the American Medical Association, 264, 998-1002.

Shaywitz, S.E. \& Shaywitz, B.A. (2005) Dyslexia (specific reading disability). Biological Psychiatry, 57, 1301-1309.

Shaywitz, S.E. \& Shaywitz, B.A. (2008). Paying attention to reading: The neurobiology of reading and dyslexia. Developmental Psychopathology, 20, 1329-1349.

Skoyles, J. \& Skottun, B.C. (2004). On the prevalence of magnocellular deficits in the visual system of non-dyslexic indivisuals. Brain and Language, 88, 79-82.

Sperling, G. (1960). The information available in brief visual presentations. Psychological Monographs, 74, 11.

Stein, J. (2001). The magnocellular theory of developmental dyslexia. Dyslexia, 7, 12-36.

Stein, J. (2012). The magnocellurar theory of dyslexia. In: A.A. Benasich and R.H. Fitch Developmental Dyslexia Early Precursors, Neurobehavioral Markers, and Biological Substrates. Brookes Publishing, Baltimore, London, Sydney, pp. 32-45.

Stein, J.F. \& Walsh, V. (1997). To see but not to read, the magnocellular theory of dyslexia. Trends in Neurosciences, 20, 229-247.

Tallal, P. (2000). The science of literacy: From the laboratory to the classroom. Procedings of the National Academy of Science USA, 97, 2402-2404.

Tamboer, P., Vorst, H.C.M., \& Oort, F.J. (2014). Five describing factors of dyslexia. Journal of Learning Disabilities, 49, 466-483.

Tree, J.J. \& Kay, J. (2006). Phonological dyslexia and phonological impairment: An exception to the rule? Neuropsychologia, 44, 2861-2873.
Underwood, G., Clews, S. \& Everatt, J. (1990). How do readers know where to look next? Local information distributions influence eye fixations. Quarterly Journal of Experimental Psychology (A), 42, 39-65.

Valtin, R. (2010). Phonologische Bewusstheit - eine notwendige Voraussetzung beim Lesen- und Schreibenlernen? leseforum.ch.

Valtin, R. (2012). Phonologische Bewusstheit: Ein kritischer Blick auf ein modisches Konstrukt. Frühe Bildung, 1, 223-225.

van der Mark, S., Klaver, P., Bucher, K., Maurer, U., Schulz, E., Brem, S. \& Brandeis, D. (2011). The left occipitotemporal system in reading: Disruption of focal fMRI connectivity to left inferior frontal and inferior parietal language areas in children with dyslexia. NeuroImage, 54, 2426-2436.

Vandermosten, M., Boets, B., Wouters, J., \& Ghesquiere, P. (2012). A qualitative and quantitative review of diffusion tensor imaging studies in reading and dyslexia. Neuroscience and Biobehavioral Reviews, 36, 1532-1552.

Wagner, R., Torgesen, J., Laughon, P., Simmons, K., \& Rashotte, C. (1993). Development of young reader's phonological processing abilities: New evidence in bi-directional causality from a latent variable longitudinal study. Developmental Psychology, 30, 73-87.

Wandell, B.A., Rauschecker, A.M., \& Yeatman, J.D. (2012). Learning to see words. Annual Review of Psychology, 63, 31-53.

Werth, R. (2001). Legasthenie und andere Lesestörungen. C. H. Beck, München.

Werth, R. (2006). Therapie von Lesestörungen durch Erkennen und Beheben der Ursachen. Ergotherapie \& Rehabilitation, 9, 6-11. 